\title{
Development of an Acoustic Sensor for On-Line Gas Temperature Measurement in Gasifiers
}

\author{
Technical Progress Report \\ Reporting Period: $\quad$ October 1, 2005 through December 31, 2005
}

Prepared for:

NETL AAD Document Control Bldg.921

US Department of Energy

National Energy Technology Laboratory

PO Box 10940

Pittsburgh, PA 15236-0940

DOE NETL Cooperative Agreement No. DE-FC26-03NT41617

Prepared by: $\quad$ Dr. Peter Ariessohn

Enertechnix, Inc.

23616 SE 225th Street

PO Box 469

Maple Valley, WA 98038

Date Issued: $\quad$ January 15, 2006

Prime Contractor: $\quad$ Enertechnix, Inc.

P.O. Box 469

Maple Valley, WA 98038

Subcontractor: ConocoPhillips

Technology Solutions Division

600 N. Dairy Ashford

Houston, TX 77079-1176

Principal Investigator: $\quad$ Peter Ariessohn, Ph.D.

Director of Research \& Development

Enertechnix, Inc.

Consultants: $\quad$ Prof. Hans Hornung

California Institute of Technology

DOE Project Officer: Kamalendu Das

U.S. Department of Energy, NETL 


\section{DISCLAIMER}

“This report was prepared as an account of work sponsored by an agency of the United States Government. Neither the United States Government nor any agency thereof, nor any of their employees, makes any warranty, express or implied, or assumes any legal liability or responsibility for the accuracy, completeness, or usefulness of any information, apparatus, product, or process disclosed, or represents that its use would not infringe privately owned rights. Reference herein to any specific commercial product, process, or service by trade name, trademark, manufacturer, or otherwise does not necessarily constitute or imply its endorsement, recommendation, or favoring by the United States Government or any agency thereof. The views and opinions of authors expressed herein do not necessarily state or reflect those of the United States Government or any agency thereof.”

\section{ABSTRACT}

This project was awarded under U.S. Department of Energy (DOE) National Energy Technology Laboratory (NETL) Program Solicitation DE-PS26-02NT41422 and specifically addresses Technical Topical Area 2 - Gasification Technologies. The project team includes Enertechnix, Inc. as the main contractor and ConocoPhillips Company as a technical partner, who also provides access to the SG Solutions Gasification Facility (formerly Wabash River Energy Limited), host for the field-testing portion of the research.

Since 1989 the U.S. Department of Energy has supported development of advanced coal gasification technology. The Wabash River and TECO IGCC demonstration projects supported by the DOE have demonstrated the ability of these plants to achieve high levels of energy efficiency and extremely low emissions of hazardous pollutants. However, a continuing challenge for this technology is the tradeoff between high carbon conversion which requires operation with high internal gas temperatures, and limited refractory life which is exacerbated by those high operating temperatures. Attempts to control internal gas temperature so as to operate these gasifiers at the optimum temperature have been hampered by the lack of a reliable technology for measuring internal gas temperatures. Thermocouples have serious survival problems and provide useful temperature information for only a few days or weeks after startup before burning out. For this reason, the Department of Energy has funded several research projects to develop more robust and reliable temperature measurement approaches for use in coal gasifiers.

Enertechnix has developed a line of acoustic gas temperature sensors for use in coal-fired electric utility boilers, kraft recovery boilers, cement kilns and petrochemical process heaters. Acoustic pyrometry provides several significant advantages for gas temperature measurement in hostile process environments. First, it is non-intrusive so survival of the measurement components is not a serious problem. Second, it provides a line-of-sight average temperature rather than a point measurement, so the measured temperature is more representative of the process conditions than those provided by thermocouples. Unlike radiation pyrometers, the measured temperature is a linear average over the full path rather than a complicated function of gas temperature and the exponential Beer's law. For this reason, acoustic pyrometry is well 
suited to tomography allowing detailed temperature maps to be created through the use of multiple path measurements in a plane. Therefore, acoustic pyrometry is an attractive choice for measuring gas temperature inside a coal gasifier.

The objective of this project is to adapt acoustic pyrometer technology to make it suitable for measuring gas temperature inside a coal gasifier, to develop a prototype sensor based on this technology, and to demonstrate its performance through testing on a commercial gasifier. The project is organized in three phases, each of approximately one year duration. The first phase consists of researching a variety of sound generation and coupling approaches suitable for use with a high pressure process, evaluation of the impact of gas composition variability on the acoustic temperature measurement approach, evaluation of the impact of suspended particles on sound attenuation, evaluation of slagging issues and development of concepts to deal with this issue, development and testing of key prototype components to allow selection of the best approaches, and development of a conceptual design for a field prototype sensor that can be tested on an operating gasifier. The second phase consists of designing and fabricating a series of prototype sensors, testing them in the lab and at a gasifier facility, and developing a conceptual design for an engineering prototype sensor. The third phase consists of designing and fabricating the engineering prototype, testing it in the lab and in a commercial gasifier, and conducting extended field trials to demonstrate sensor performance and investigate the ability to improve gasifier performance through the use of the sensor. 


\section{TABLE OF CONTENTS}

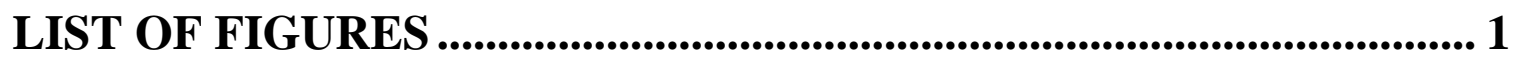

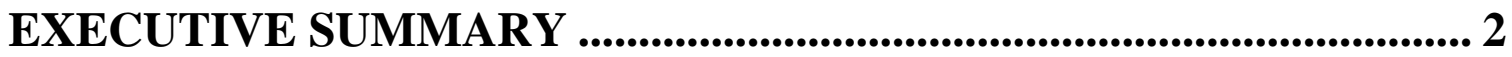

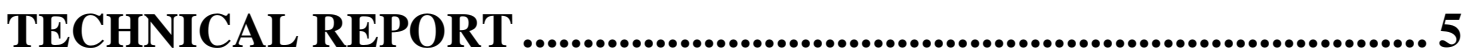

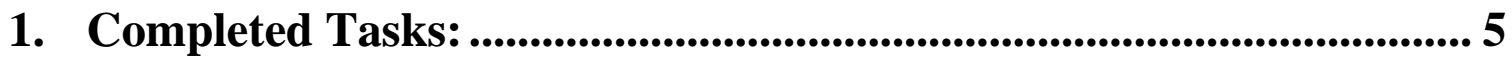

2. Key Milestone Updates .....................................................................5 5

3. Issues Requiring DOE Attention: ................................................. 5

4. Significant Accomplishments: .................................................................. 5

5. Timeline for FY05 and FY06 ........................................................9

\section{LIST OF FIGURES}

Figure 1. Measurement of structural beam interference......................... 6

Figure 2. Side view of reconfigured auto-GAP sensor. ................................ 7

Figure 3. Back view of reconfigured auto-GAP sensor ............................... 7 


\section{EXECUTIVE SUMMARY}

Since 1989 the U.S. Department of Energy has supported development of advanced coal gasification technology. The Wabash River and TECO IGCC demonstration projects supported by the DOE have demonstrated the ability of these plants to achieve high levels of energy efficiency and extremely low emissions of hazardous pollutants. However, a continuing challenge for this technology is the tradeoff between high carbon conversion which requires operation with high internal gas temperatures, and limited refractory life which is exacerbated by those high operating temperatures. Attempts to control internal gas temperature so as to operate these gasifiers at the optimum temperature have been hampered by the lack of a reliable technology for measuring internal gas temperatures. Thermocouples have serious survival problems and provide useful temperature information for only a few days or weeks after startup before burning out. For this reason, the Department of Energy has funded several research projects to develop more robust and reliable temperature measurement approaches for use in coal gasifiers.

Enertechnix has developed a line of acoustic gas temperature sensors for use in coal-fired electric utility boilers, kraft recovery boilers, cement kilns and petrochemical process heaters. Acoustic pyrometry provides several significant advantages for gas temperature measurement in hostile process environments. First, it is non-intrusive so survival of the measurement components is not a serious problem. Second, it provides a line-of-sight average temperature rather than a point measurement, so the measured temperature is more representative of the process conditions than a thermocouple measurement. Unlike radiation pyrometers, the measured temperature is a linear average over the full path rather than a complicated function of gas temperature and the exponential Beer's law. For this reason, acoustic pyrometry is well suited to tomography allowing detailed temperature maps to be created through the use of multiple path measurements in a plane. Therefore, acoustic pyrometry is an attractive choice for measuring gas temperature inside a coal gasifier.

The objective of this project is to adapt acoustic pyrometer technology to make it suitable for measuring gas temperature inside a coal gasifier, to develop a prototype sensor based on this technology, and to demonstrate its performance through testing on a commercial gasifier. The project is organized in three phases, each of approximately one year duration. Phase I consists of researching a variety of sound generation and coupling approaches suitable for use with a high pressure process, evaluation of the impact of gas composition variability on the acoustic temperature measurement approach, evaluation of the impact of suspended particles on sound attenuation, evaluation of slagging issues and development of concepts to deal with this issue, development and testing of key prototype components to allow selection of the best approaches, and development of a conceptual design for a field prototype sensor that can be tested on an operating gasifier. Phase II consists of designing and fabricating a series of prototype sensors, testing them 
in the lab, and developing a conceptual design for an engineering prototype sensor. Phase III consists of designing and fabricating the engineering prototype, testing it in the lab and in a commercial gasifier, and conducting extended field trials to demonstrate sensor performance and investigate the ability to improve gasifier performance through the use of the sensor.

In year 1 Enertechnix accomplished all of the goals of phase I. Experiments were conducted on a variety of sound generation and coupling methods and a suitable approach was identified and successfully demonstrated on a gasifier simulator that Enertechix constructed for this project. The selected approach employs a shock tube which is driven by the high pressure gases which exist within the gasifier itself, obviating the need for an external source of high pressure gas. Experiments with a prototype device demonstrated the ability to produce strong sound pulses with very sharp edges and the ability to utilize the propagation time of these pulses in the gasifier simulator to accurately measure gas temperature.

The effect of gas composition variation was investigated using CFD modeling data provided by Reaction Engineering, International, and process information supplied by ConocoPhillips Company. The impact of suspended particles in the gasifier environment was investigated through computational modeling and found to be tolerable in environments typical of entrained flow gasifiers. A conceptual design for a field prototype sensor was developed that incorporates provision for slag rodding to maintain clear acoustic access to the gasifier interior.

In year 2 Enertechnix developed and successfully tested several laboratory prototypes. At the end of year 2 a fully functional field prototype sensor was designed and fabrication was nearly complete. Arrangements for installation on the Wabash River gasifier were in progress.

In year 3 Enertechnix has completed fabrication of the first field prototype sensor ("autoGAP”) and has carried out a series of tests at its facilities in Tenino, WA. Arrangements for installation at the Wabash River plant have been finalized. During the previous reporting period, the need for a major reconfiguration of the sensor was discovered due to the presence of a structural beam at the Wabash River plant in a location that would have interfered with the sensor housing in its initial configuration. Unanticipated complications associated with that reconfiguration have delayed the start of field testing which is now scheduled to take place in January, 2006. Detailed CFD modeling of the current configuration of our prototype sensor has been completed and a model of the required end corrections has been generated to allow for accurate temperature measurements in the gasifier. Work is nearly complete on the software used to fully automate the operation of the sensor and the data collection process. We are also working on modifications to our existing software that automatically analyzes the collected waveforms and converts these raw signals into temperature readings. 


\section{Enertechnix, Inc.}

In September Dr. Ariessohn attended the Pittsburgh Coal Conference and presented a paper on the project. Several companies expressed interest in the project and Enertechnix is currently following up on several potential alliances. 


\section{TECHNICAL REPORT}

\section{Completed Tasks:}

- Budget Period 1, All tasks completed

- Budget Period 2, All tasks completed

- Budget Period 3, Task 1: Detailed Interfacing Plan Development

- Budget Period 3, Task 2: Engineering Prototype Design and Fabrication

- Budget Period 3, Task 3: Engineering Prototype Laboratory Testing

- Budget Period 3, Task 6: Sensor Modification

\section{Key Milestone Updates}

- Budget Period 3, Task 7, Sensor Retesting nearly complete

- Budget Period 3, Task 5: Field Testing - Scheduled for January, 2006

\section{Issues Requiring DOE Attention:}

- Delay in prototype testing due to Wabash River plant shutdowns.

\section{Significant Accomplishments:}

- Reconfiguration of field prototype sensor completed

- Retesting of field prototype at Enertechnix nearly complete

- Interfacing arrangements completed

- Automation software complete and operational

These accomplishments are described below:

\subsection{Reconfiguration of field prototype sensor completed}

Following completion of testing of the "auto-GAP" (automated Gasifier Acoustic Pyrometer) sensor on the EGS1 unit at Enertechnix facilities in Tenino, WA in September, the unit was removed from the EGS1 unit and dismantled. A design for reconfiguring the sensor was developed based on field measurements of the location of the structural beam at the Wabash River plant carried out by plant engineering personnel. Figure 1 shows an example of measurements that were performed to accurately define the location and orientation of the beam relative to the sensor mounting location. From measurements of axial and radial distances and the angle from the horizontal to the point of intersection between the beam and a plane perpendicular to the sensor axis, a model of the beam was developed and incorporated into our SolidWorks model of the sensor. This allowed us to determine the necessary rearrangement of the sensor components to ensure adequate clearance at the plant. 


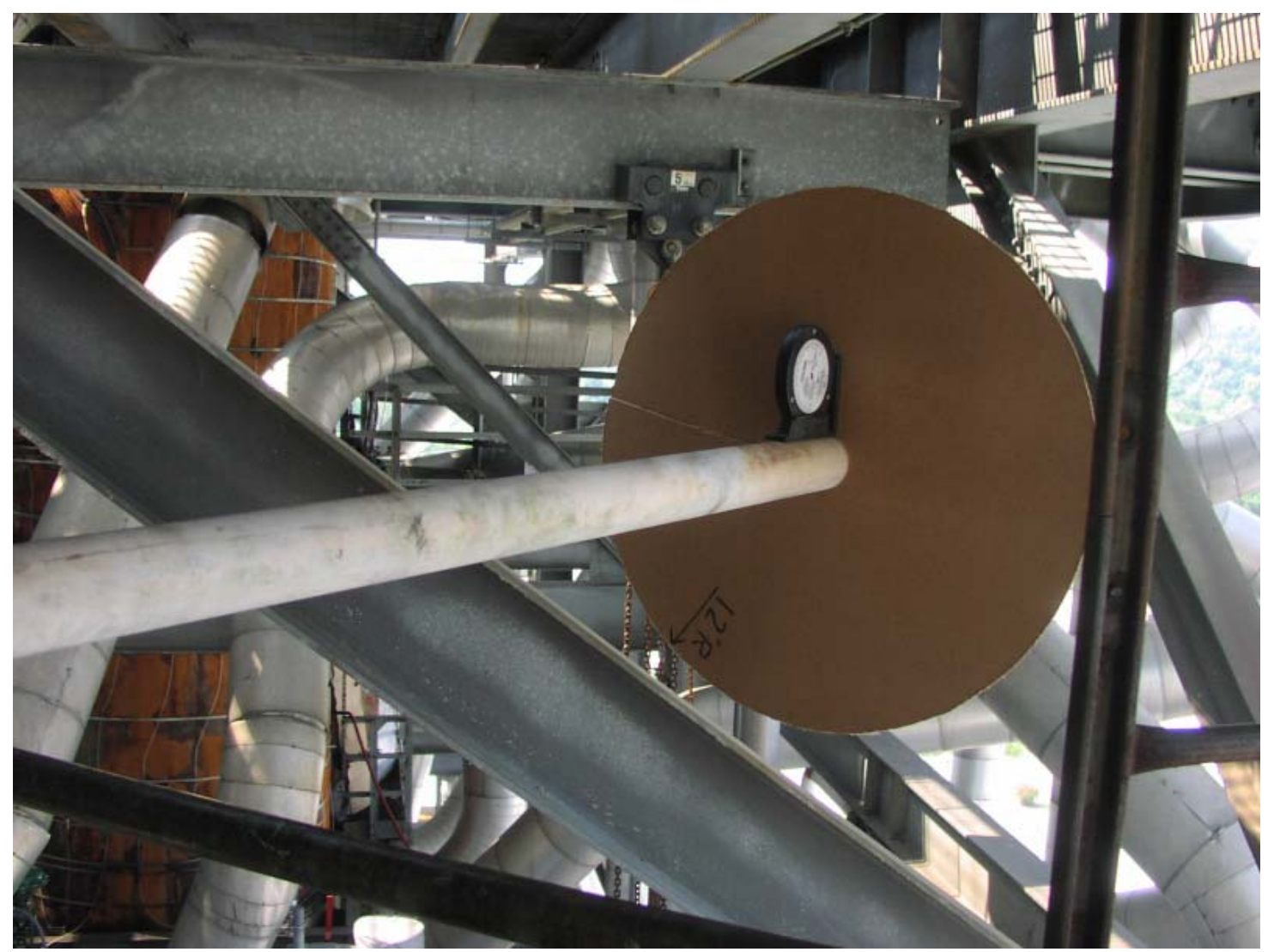

Figure 1. Measurement of structural beam interference.

From this model it was determined that the simplest rearrangement involved moving the electronics enclosure on the sound generator unit to the opposite side of the sensor and re-mounting to the sensor framework in its new location. This required re-plumbing many of the control lines that operate the pneumatic controls and rewiring most of the electrical connections. In addition, it was necessary to redesign the framework and the external sheet metal to avoid interference with the structural beam. At the same time, we took the opportunity to lower the diaphragm material supply spool to provide increased clearance between the spool and the deck above the mounting location, and we also repositioned most of the control valves to minimize the length of tubing and to generally "clean up" the sensor layout.

The reconfiguration of the sensor was completed in late November and it was re-installed on the EGS1 unit in early December. Figure 2 andFigure 3 show the reconfigured generator unit of the sensor installed on the EGS1 unit. 
Enertechnix, Inc.

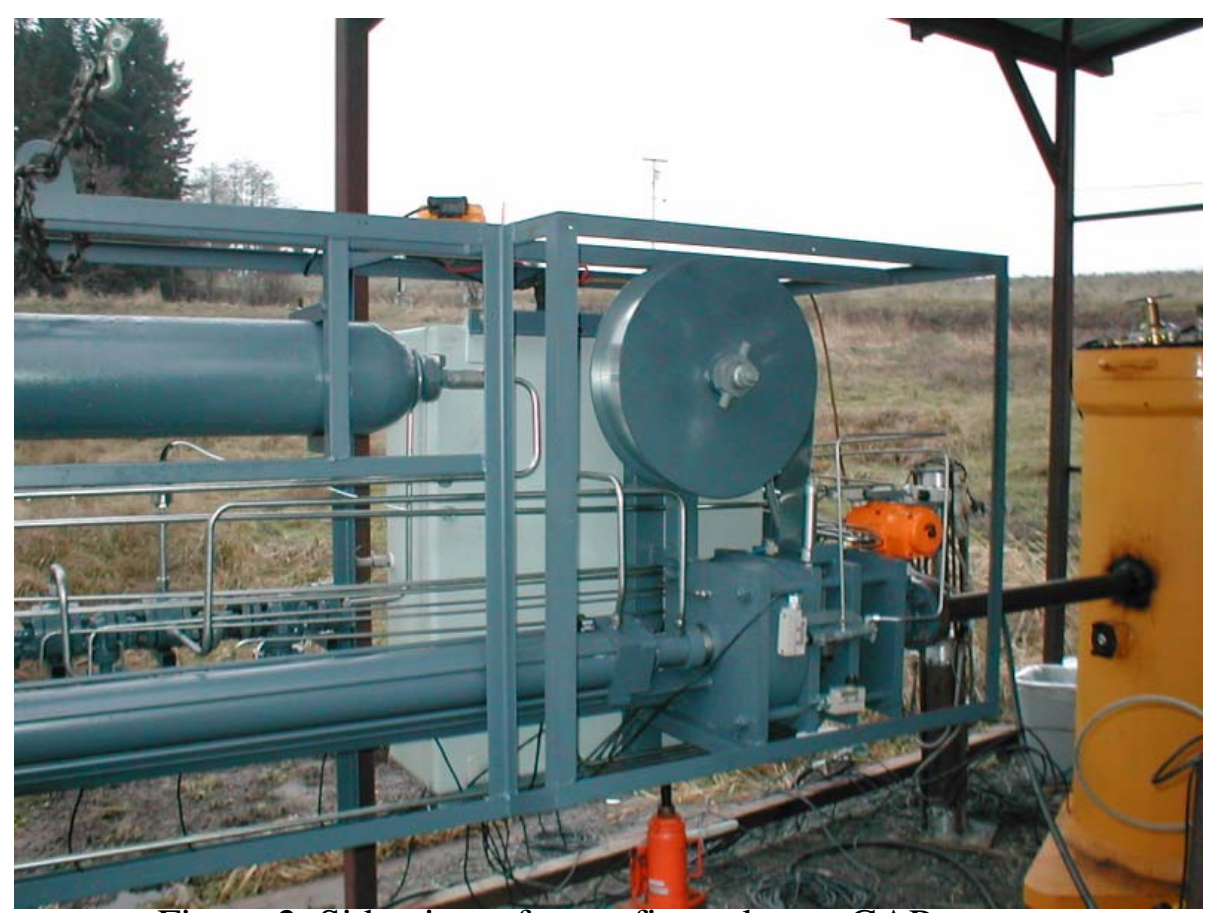

Figure 2. Side view of reconfigured auto-GAP sensor.

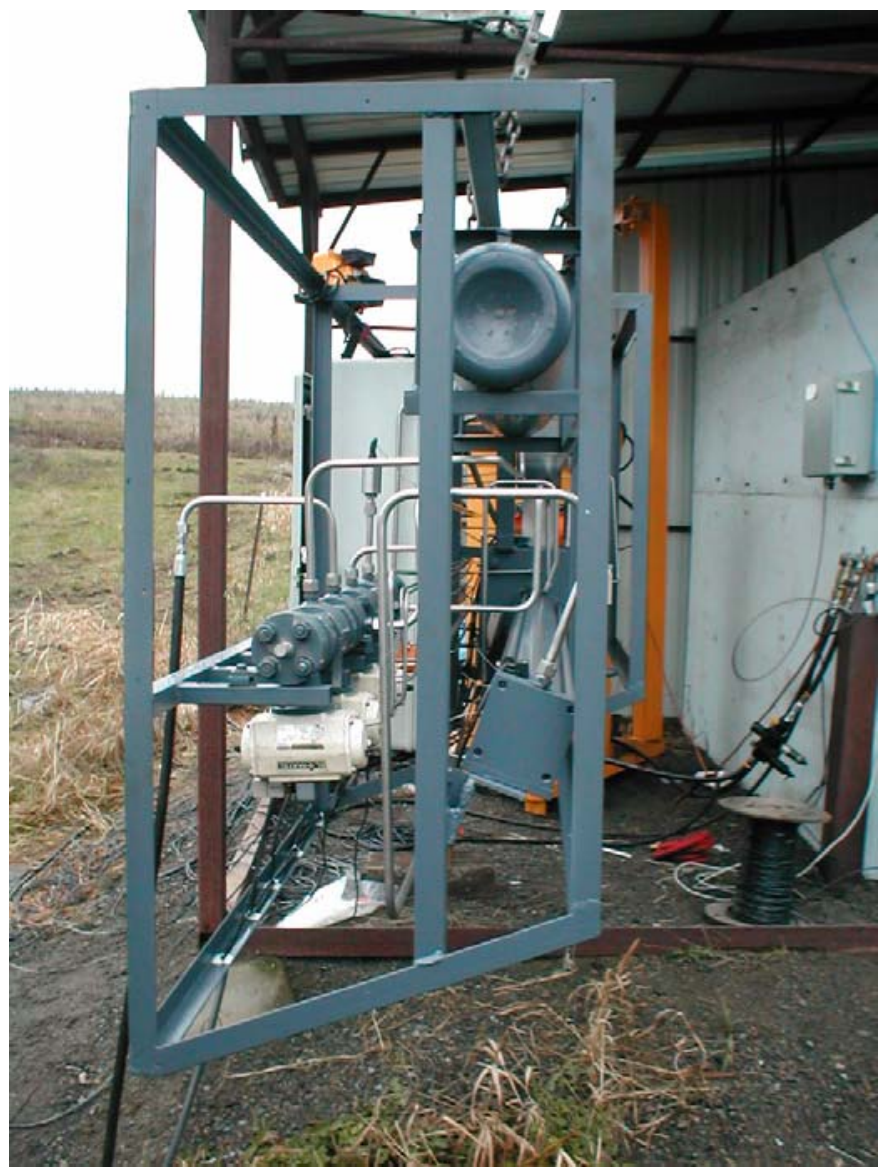

Figure 3. Back view of reconfigured auto-GAP sensor 


\subsection{Retesting of field prototype at Enertechnix nearly complete}

Following installation of the reconfigured sensor on the EGS1 unit, it was necessary to reconnect all the plumbing and wiring and retest the functionality of all of the sensor components. Pressure tests were performed to ensure proper sealing of all components. A recurring problem with the Galil motion control computer that had not previously been diagnosed was traced to a ground loop problem that was corrected by adding a separate power supply. A problem we had noted earlier with the static pressure transducers that are used to verify proper sensor operation and to detect leaks was resolved by replacing the intrinsically safe barriers with a new version that has proved to be much better suited to our application. Several other issues of this sort were addressed and resolved and we are now confident that the electrical performance of the sensor is sound and reliable.

We intend to complete testing of the reconfigured sensor by early January and ship the sensor to Wabash River for testing in mid- to late-January.

\subsection{Interfacing arrangements completed}

Final discussions with Wabash River engineering personnel during December, 2005 appear to have raised no additional concerns and we believe that the sensor, in its current configuration, meets or exceeds all plant requirements. We will have a final review meeting with plant personnel during January during our visit to install and test the sensor. Barring any unforeseen developments, we believe this review meeting will assure the plant that the sensor and our planned test will pose no significant hazards.

During the visit in January, it will be necessary to mount the sensor components, run conduit and wiring, and install and connect plumbing. These tasks should be routine and we anticipate no difficulties in accomplishing them within two or three days. Following the installation, we will conduct several days of testing.

\subsection{Automation software complete and operational}

As explained in the previous quarterly report, automation of the operation of the autoGAP sensor is accomplished through a multi-level computer control system. At the lowest level, a Galil programmable motion controller is used to command pneumatic actuators which actuate valves and other devices such as the port rodding cylinders and diaphragm material feed actuators. The Galil controller also accepts inputs from a number of sensors such as limit switches and pressure and temperature sensors that are used to ensure the proper operation of the system and to provide the ability to perform a safe shutdown in the event of a malfunction. The Galil motion controller is under the supervisory control of a system computer which handles communication with the outside world, stores data and passes instructions to the Galil controller when a firing sequence should be initiated. Data acquisition is currently being handled by a PC running LabView which will be placed in the control room and will communicate with the system computer. In future versions, the system computer will handle the functions now being handled by the PC - waveform analysis, conversion of timing data into temperature, and 
reporting to the DCS. The PC is now being used to collect and analyze waveforms from the ultrasonic transducers used to measure the shock wave produced by the sensor. Software has been developed and tested to enable each of these computers to carry out their respective functions. The software has now been tested and debugged and is functioning properly.

Prior to reconfiguring the sensor, a successful lab test of the entire system operating autonomously was conducted. We plan to repeat this test with the reconfigured sensor prior to shipping the system to Wabash River in January.

\section{Timeline for FY05 and FY06}

The following Gantt chart shows our best estimate of the project schedule going forward.

In this chart Quarter 10 of the project is the current quarter $\left(4^{\text {th }}\right.$ calendar quarter, 2005)

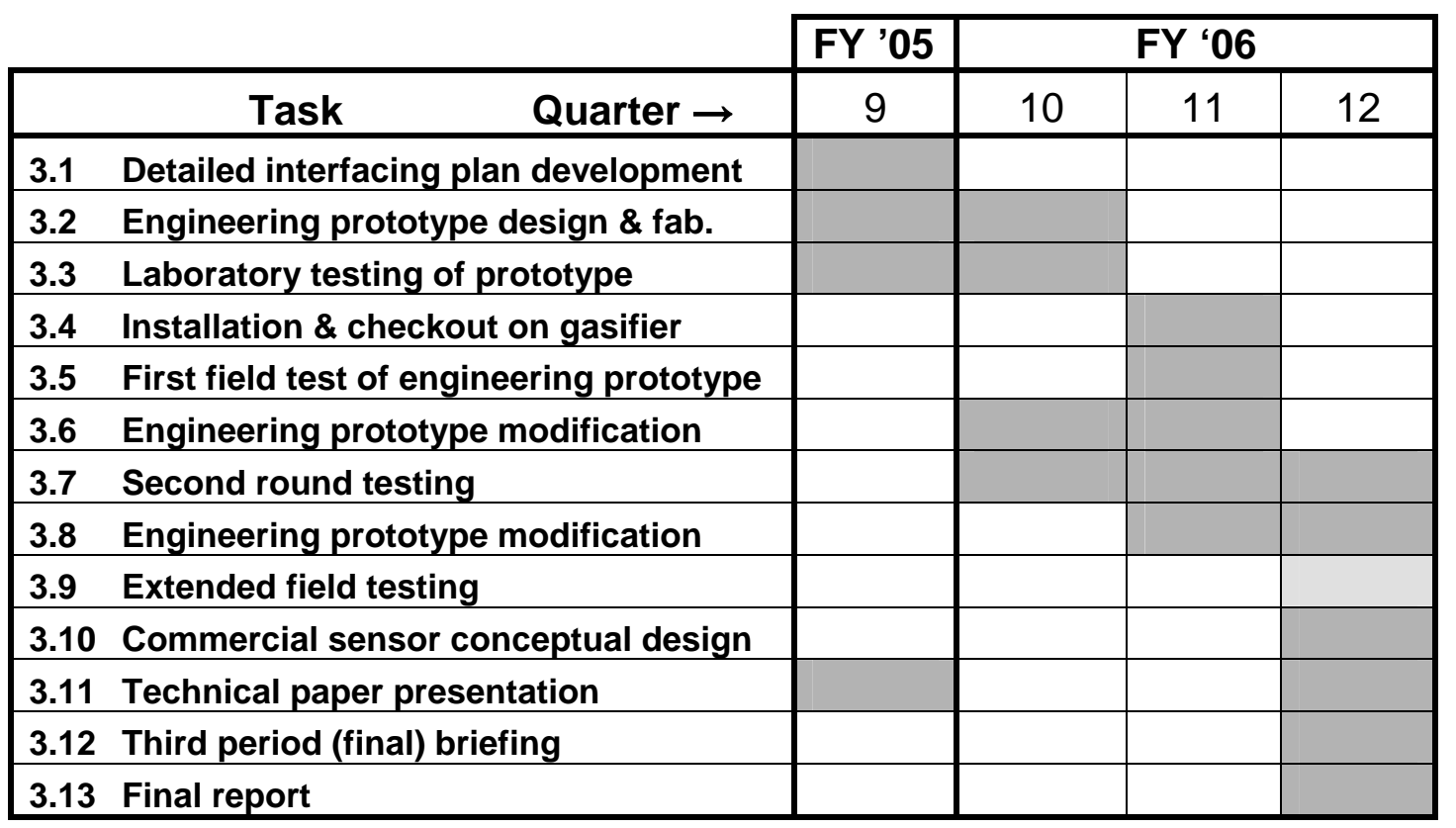

The activity shown on tasks 3.6 and 3.7 refer to the reconfiguration and subsequent lab testing of the auto-GAP sensor. Given the delays that we have experienced due to unanticipated plant outages and the stringent engineering requirements imposed by the plant, it now appears that completion of all testing originally envisioned, may not be possible within the time and resources remaining. For this reason, task 3.9 is shown with light shading to reflect this uncertainty. We do intend to complete at least two rounds of plant testing and it is our hope that these tests will adequately demonstrate the viability of the measurement technique and the efficacy of our sensor. 